\title{
Prevalence and Correlates of Previous Hepatitis B Vaccination and Infection Among Young Drug-users In New York City
}

\author{
S. Amesty - D. C. Ompad - S. Galea · C. M. Fuller • \\ Y. Wu $\cdot$ B. Koblin $\cdot$ D. Vlahov
}

Published online: 10 January 2008

(C) Springer Science+Business Media, LLC 2008

\begin{abstract}
Hepatitis B (HBV) vaccination coverage remains low among drug users. In 1997, ACIP made hepatitis $B$ vaccine available for persons aged $0-18$ years and many states began requiring $\mathrm{HBV}$ vaccination for entry into middle school; these programs might affect HBV vaccination and infection rates in younger DUs. We were interested in determining correlates of immunization among younger ( $<25$ years) and older ( 25 and older) DUs. Methods: A community-based sample of 1,211 heroin, crack, and cocaine users 18 or older was recruited from Harlem and the Bronx. We assessed previous HBV
\end{abstract}

\section{S. Amesty}

College of Physicians and Surgeons, Center for Family and Community Medicine, Columbia University, $630 \mathrm{~W}$ 168th Street, New York, NY 10032, USA

D. C. Ompad $(\bowtie) \cdot$ S. Galea · C. M. Fuller · D. Vlahov Center for Urban Epidemiologic Studies, New York Academy of Medicine, 1216 Fifth Avenue, New York, NY 10029, USA e-mail: dompad@nyam.org

S. Galea

Department of Epidemiology, University of Michigan School of Public Health, Ann Arbor, MI 48109, USA

C. M. Fuller · B. Koblin · D. Vlahov

Department of Epidemiology, Mailman School of Public Health, Columbia University, 722 W 168th Street, New York, NY 10032, USA

Y. Wu

Center for the Study of Hepatitis C, Weill Medical College of Cornell University, 411 E 69th Street, Room KB200-A, New York, NY 10021, USA

B. Koblin

New York Blood Center, 63 W 87th Street, New York, NY 10024, USA vaccination and infection and correlates using bivariate analyses. Results: The sample was predominantly male (74.0\%), aged $\geq 25$ years (67.1\%) and Hispanic (59.9\%). In terms of socioeconomic status, $57.1 \%$ had less than a high school education, $84.5 \%$ had been homeless in their lifetime, and $48.0 \%$ had an illegal main income source. Among 399 DUs younger than 25 years of age, 30\% demonstrated serological evidence of previous vaccination, 49.9\% were susceptible to HBV at baseline, and $20 \%$ showed evidence of infection. In our model, previous HBV infection and vaccination status were associated with being 22 years old or younger ( $\mathrm{AOR}=1.40$ and 1.66). Compared to susceptible individuals, those vaccinated were significantly less likely to be born in other countries $(\mathrm{AOR}=0.50)$. Among 812 DUs 25 and older, $10.6 \%$ demonstrated serological evidence of previous vaccination, $59.2 \%$ were susceptible to HBV at baseline, and $30.2 \%$ showed evidence of infection. Conclusion: Existing interventions to increase $\mathrm{HBV}$ vaccination among adolescents should target high risk groups.

Keywords Hepatitis B - Substance use - Vaccination

\section{Introduction}

Hepatitis B virus (HBV) infection continues to be a major public health concern in the 21st century, with an estimated 1.25 million Americans being chronic carriers and an estimated 5,000 deaths from chronic liver disease each year [1-5]. Parenteral transmission of HBV through injection drug use practices accounts for more than half of all HBV cases [6]. Additionally, the prevalence of HBV infection among injection drug users (IDUs) ranges between $40 \%$ and $81 \%[7,8]$. 
An effective recombinant $\mathrm{HBV}$ vaccine has been available for more than 20 years. Introduced into the childhood immunization schedule in the US in 1991 [9, 10], the HBV vaccine has been recommended for a variety of individuals including those at occupational risk of infection (e.g. health care workers), men who have sex with men (MSM), sexually transmitted disease (STD) patients, and IDUs [9]. Despite these strategies to reduce $\mathrm{HBV}$, the estimated number of new hepatitis B infections was still 60,000 in 2004; adults accounted for $95 \%$ of the cases; the majority registered among the 25-44 year old group, followed by the 15-24 year old and the older than 45 groups; in general, vaccination rates remain low in adult high risk groups [11].

$\mathrm{HBV}$ vaccination is required for entry into middle school in 37 of the 50 states and the District of Columbia since 1997 or later. In addition, in 1995, the Advisory Committee on Immunization Practices (ACIP) recommended vaccination of all unvaccinated children 11 years of age and younger, and in 1997, this recommendation was expanded to all unvaccinated adolescents aged 18 and younger [12]. These mandates and recommendations should result in higher vaccination rates in younger adults. However, some adolescents and young adults in high risk groups, who should have been part of the group covered by these recommendations and HBV vaccination programs have been, and continue to be, missed by these vaccination programs and catch-up schemes and thus remain susceptible to HBV. This has been implied in studies of HBV and younger IDUs and even lower vaccination rates have been reported in studies of younger MSM aged 15-22 years, where vaccination coverage is $9 \%$ despite $90 \%$ reporting regular access to health care [13]. Clearly, many adolescents are slipping through the cracks and not receiving HBV vaccination.

In this study we aimed to compare the serologic prevalence and correlates of previous HBV infection and vaccination among younger (less than 25 years old) and older (25 and older) IDUs and NIDUs among new recruits to a prospective study of young injection and non-injection heroin, crack, and cocaine users in Harlem and the South Bronx in New York City.

\section{Methods}

\section{Subject Recruitment}

Potential participants were recruited for two ongoing studies of NIDUs and IDUs using street outreach techniques, as described elsewhere [14, 15]. Briefly, outreach workers engaged drug users in conversations about ongoing research at the research storefront at places in the community where drugs were bought and/or used. Both IDUs and NIDUs were recruited between 2000 and 2004.
Potential participants completed a screening demographic interview. The IDU study was designed to study correlates and predictors of hepatitis $\mathrm{C}$ infection and therefore targeted young, recently initiated IDUs at risk for $\mathrm{HCV}$ infection. Participants were eligible for the injector part of the study if they were age 15-40 years and reported injecting drug use of heroin or cocaine at least once in the last 2 months but for no longer than 5 years. The NIDU study was aimed at investigating correlates and predictors of transition to injection drug use, and therefore recruited young NIDUs. Participants were eligible for the noninjector part of the study if they were age 15-40 years and reported non-injecting drug use of heroin or cocaine at least 2-3 times in the last 2 months but for no longer than 10 years, and no history of injecting drug use. Participants were reimbursed \$20 for their participation. The study was approved by the institutional review boards of the New York Academy of Medicine and the New York Blood Center. Informed consent was obtained from all study participants and guidelines for human experimentation of the US Department of Health and Human Services and the authors' institutions were followed in the conduct of this research protocol.

\section{Data Collection}

Following informed consent, eligible participants completed a standardized, detailed risk behavior questionnaire administered by trained interviewers. We asked about the type, frequency, and duration of their drug use, and the use and sharing of drug equipment. We also asked participants about their vaccination and medical histories. The lack of prior drug use by injection was confirmed during the comprehensive interviewing process and by phlebotomists' observations during venipuncture.

Demographic characteristics considered included age, race, gender, socioeconomic status (SES), and ever being homeless. Several variables were used to assess SES including education, homelessness, main income source (e.g. employed, illegal, or public assistance) and income. In terms of risk behaviors, our analysis focused on drug use, drug treatment and potential opportunities for exposure to HBV through drug use behaviors (e.g. injection drug use) and sexual partners (e.g. IDUs, MSM and hepatitis-infected sex partners). The question regarding hepatitis-infected sex partners did not differentiate between different hepatitides.

HBV Testing, Counseling, and Referrals

Following completion of the interview, all participants were counseled about hepatitis B, hepatitis C, and HIV 
infection and had a blood specimen drawn for serologic testing. Serology samples were tested for HBV, HCV and HIV. HBV testing consisted of detection of Hepatitis B surface antigen (HBsAg: Abbott Laboratories, Abbott Park, IL), antibodies to hepatitis B surface antigen (anti-HBs: Ortho Clinical Diagnostics, Inc, Raritan, NJ) and antibodies to hepatitis B core antigen (anti-HBc: Ortho Clinical Diagnostics Inc, Raritan, NJ). HCV antibodies were detected by enzyme-linked immunosorbant assay (ELISA) (Ortho HCV Version 2.0 ELISA). Sera that were reactive on the first testing were retested in duplicate. Repeatedly reactive samples were confirmed by strip immunoblot assay (Chiron RIBA HCV 3.0 SIA). HIV antibodies were detected using enzyme-linked immunosorbant assay (EIA) for HIV types 1 and 2 (Abbott Laboratories, Abbott Park, IL) with a confirmatory Western for HIV type 1 (Calypte Biomedical Corporation, Alameda, CA).

Participants returned two to three weeks later to learn their test results and receive referrals for medical care and other health and social services. Participants who were immune to HBV by previous infection or vaccination were informed of their serostatus. Participants who were found to be HBV susceptible were informed that they were HBV negative and encouraged to receive vaccination through one of our community partners, as has been described elsewhere [16].

\section{Statistical Methods}

We compared participants who had serologic evidence of previous HBV vaccination (anti-HBs positive, HBsAg and anti-HBc negative) or previous/current HBV infection (HBsAg and/or anti-HBc positive) at baseline to those who were susceptible to $\mathrm{HBV}$ at baseline (HBsAg, anti-HBs and anti-HBc negative), stratified by age (younger than 25 years of age versus 25 and older). We described demographic characteristics among the susceptible and vaccinated groups, in addition to drug use and sexual behaviors.

Bivariate analyses were conducted to examine demographic and risk behavior variables by vaccination status using $\chi^{2}$ statistics. Covariates that were significantly associated with vaccination status in bivariate analyses $(P<0.20)$ were entered into a final multivariate polychotomous generalized logit model. Covariates that did not remain significant in the model $(P<0.05)$ were removed.

We also sought to determine the reliability of selfreported vaccination among this population of substance users. Using serological evidence of $\mathrm{HBV}$ vaccination (serologic response to anti-HBs only) as the "gold standard," we determined the specificity and sensitivity of selfreported HBV vaccination.

\section{Results}

Among the 1,211 subjects enrolled in the study, $26.8 \%$ had serologic evidence of $\mathrm{HBV}$ infection, $56.2 \%$ were susceptible to HBV at baseline, and $17.0 \%$ demonstrated serological evidence of previous vaccination. The prevalence of HBV infection among IDUs was $35.8 \%$; however the prevalence of HBV infection among NIDUs was not inconsiderable at $22.7 \%$. The sample was predominantly male $(74.0 \%)$, aged 25 and older $(67.1 \%)$, heterosexual $(85.0 \%)$ and Hispanic $(59.9 \%)$. In terms of socioeconomic status, $57.1 \%$ had less than a high school education, $84.5 \%$ had been homeless in their lifetime, and $48.0 \%$ had an illegal main income source.

Because self-reported HBV vaccination was a significant correlate of vaccination, we evaluated the reliability of self-report in this population. Overall, approximately $27.7 \%$ of participants self-reported being previously vaccinated against HBV. Of those who self-reported having at least one dose of $\mathrm{HBV}$ vaccine, $32.6 \%$ were anti-HBs positive. The concordance between the serologic results and self-report was high $(73.8 \%)$. The sensitivity and specificity for self-reported HBV vaccination was $48.5 \%$ and $79.0 \%$, respectively. Kappa statistic for comparison between self-reported and serologic evidence of vaccination was 0.23 .

HBV Among Participants Less Than 25 year Old

Among the 399 participants younger than 25 years of age, $50 \%$ were susceptible to HBV, $20 \%$ showed evidence of infection, and $30 \%$ had serologic evidence of vaccination. Participants younger than 25 years of age (Table 1) were predominantly male $(78.9 \%)$ and Hispanic $(71.7 \%)$. About one third of participants $(30.5 \%)$ had a high school diploma or equivalent, $82.6 \%$ had been homeless in their lifetime, and $57.7 \%$ had an illegal main source of income. We compared participants less than 25 years of age who were susceptible to HBV to those who were vaccinated or infected, based on serological findings at baseline with respect to sociodemographic characteristics. Those with evidence of HBV infection were more likely to be HIV and $\mathrm{HCV}$ infected than those who were susceptible to or previously vaccinated for, HBV. Those with evidence of HBV infection were more likely to have been born in Puerto Rico than those vaccinated or susceptible.

Table 2 describes drug use and sexual behaviors stratified by HBV serostatus. Eleven percent of NIDUs showed evidence of HBV infection compared to $31 \%$ of IDUs. Those infected with HBV were more likely to have been in a drug/ alcohol treatment program. Among IDUs, those infected with HBV were more likely to inject daily and attend a 
Table 1 Sociodemographic characteristics of drug users in Harlem and the South Bronx by serologic evidence of HBV vaccination, stratified by age

\begin{tabular}{|c|c|c|c|c|c|c|}
\hline & \multicolumn{3}{|l|}{ Age $<25$ years } & \multicolumn{3}{|c|}{ Age $=$ or $>25$ years } \\
\hline & $\begin{array}{l}\text { Vaccinated } \\
(n=120) \%\end{array}$ & $\begin{array}{l}\text { Susceptible } \\
(N=199) \%\end{array}$ & $\begin{array}{l}\text { Infected } \\
(n=80) \%\end{array}$ & $\begin{array}{l}\text { Vaccinated } \\
(n=86) \%\end{array}$ & $\begin{array}{l}\text { Susceptible } \\
(N=481) \%\end{array}$ & $\begin{array}{l}\text { Infected } \\
(n=245) \%\end{array}$ \\
\hline \multicolumn{7}{|l|}{ Gender } \\
\hline Male & 82.4 & 79.1 & 73.1 & 70.6 & 73.5 & 68.3 \\
\hline Female & 17.7 & 20.9 & 26.9 & 29.4 & 26.5 & 31.7 \\
\hline \multicolumn{7}{|l|}{ Age } \\
\hline$<22$ & 60.0 & 37.2 & $45.0^{\mathrm{a}}$ & - & - & - \\
\hline$\geq 22$ & 40.0 & 62.8 & 55.0 & & & \\
\hline \multicolumn{7}{|l|}{ Race } \\
\hline Hispanic & 68.3 & 71.9 & 76.3 & 54.7 & 54.7 & 52.7 \\
\hline Black & 15.0 & 15.1 & 13.8 & 39.5 & 34.3 & 41.2 \\
\hline White/other & 16.7 & 13.1 & 10.0 & 5.8 & 11.0 & 6.1 \\
\hline \multicolumn{7}{|l|}{ Sexual orientation } \\
\hline Heterosexual & 11.1 & 13.9 & 19.5 & 89.3 & 87.7 & $76.7^{\mathrm{a}}$ \\
\hline Homosexual/bisexual & 88.9 & 86.1 & 80.5 & 10.7 & 12.3 & 23.3 \\
\hline \multicolumn{7}{|l|}{ Homeless } \\
\hline Never & 20.2 & 17.1 & 13.9 & 11.6 & 17.7 & $9.4^{\mathrm{a}}$ \\
\hline Ever & 79.8 & 82.9 & 86.1 & 88.4 & 82.3 & 90.6 \\
\hline \multicolumn{7}{|l|}{ Birth place } \\
\hline USA & 66.7 & 58.7 & $37.5^{\mathrm{a}}$ & 80.0 & 71.8 & 65.3 \\
\hline Puerto Rico & 28.3 & 27.6 & 55.0 & 14.1 & 18.6 & 25.7 \\
\hline Others & 5.0 & 13.8 & 7.5 & 5.9 & 9.6 & 9.0 \\
\hline \multicolumn{7}{|l|}{ Main income source } \\
\hline Employed & 16.1 & 13.0 & 10.3 & 11.8 & 21.9 & $16.6^{\mathrm{b}}$ \\
\hline Illegal & 61.9 & 52.1 & 65.4 & 40.0 & 42.6 & 45.5 \\
\hline Public assistance & 13.6 & 16.7 & 11.5 & 36.5 & 22.4 & 21.7 \\
\hline Others & 8.5 & 18.2 & 12.8 & 11.8 & 42.6 & 16.2 \\
\hline \multicolumn{7}{|l|}{ HCV infection } \\
\hline No & 74.8 & 84.8 & $37.2^{\mathrm{a}}$ & 81.4 & 86.0 & $67.4^{\mathrm{a}}$ \\
\hline Yes & 25.2 & 15.2 & 62.8 & 18.6 & 14.0 & 32.6 \\
\hline \multicolumn{7}{|l|}{ HIV infection } \\
\hline No & 93.3 & 98.5 & $91.1^{\mathrm{b}}$ & 90.7 & 93.1 & $76.5^{\mathrm{a}}$ \\
\hline Yes & 6.7 & 1.5 & 8.9 & 9.3 & 6.9 & 23.5 \\
\hline \multicolumn{7}{|c|}{ Self-reported HBV vaccination } \\
\hline No & 56.1 & 72.3 & $77.8^{\mathrm{a}}$ & 41.5 & 80.4 & $74.8^{\mathrm{a}}$ \\
\hline Yes & 43.9 & 27.7 & 22.2 & 58.5 & 19.6 & 25.2 \\
\hline
\end{tabular}

${ }^{\mathrm{a}} P \leq 0.01$

${ }^{\mathrm{b}} P \leq 0.05$

shooting gallery (data not shown) and to have use heroin daily in the last 6 months when compared to susceptible and vaccinated participants. Although not statistically significant, those who reported needle sharing were more likely to be infected; however, $45.7 \%$ of susceptible IDUs reported sharing needles and $34.3 \%$ of susceptible IDUs attended a shooting gallery (data not shown).

In a final multivariable polychotomous logit model (Table 3) with "uninfected/no serological evidence of vaccine" as the reference, we found that both previous HBV infection and vaccination were associated with $\mathrm{HCV}$ and HIV seropositivity $(\mathrm{AOR}=3.14$ and 1.51 for $\mathrm{HCV}$, and AOR $=2.96$ and 2.30 for HIV, respectively). Previous HBV infection and vaccination status were associated with being 22 years old or younger $(\mathrm{AOR}=1.40$ and $\mathrm{AOR}=1.66$, respectively).

Compared to susceptible individuals, those vaccinated were significantly less likely to be born in other countries $(\mathrm{AOR}=0.50)$. 
Table 2 Sexual and drug use behaviors of drug users in Harlem and the South Bronx by serologic evidence of HBV vaccination, stratified by age

\begin{tabular}{|c|c|c|c|c|c|c|}
\hline & \multicolumn{3}{|l|}{ Age $<25$ years } & \multicolumn{3}{|c|}{ Age $=$ or $>25$ years } \\
\hline & $\begin{array}{l}\text { Vaccinated } \\
(n=120) \%\end{array}$ & $\begin{array}{l}\text { Susceptible } \\
(N=199) \%\end{array}$ & $\begin{array}{l}\text { Infected } \\
(n=80) \%\end{array}$ & $\begin{array}{l}\text { Vaccinated } \\
(n=86) \%\end{array}$ & $\begin{array}{l}\text { Susceptible } \\
(N=481) \%\end{array}$ & $\begin{array}{l}\text { Infected } \\
(n=245) \%\end{array}$ \\
\hline \multicolumn{7}{|l|}{ IDU } \\
\hline No & 58.3 & 64.3 & $31.3^{\mathrm{a}}$ & 73.3 & 78.4 & $66.1^{\mathrm{a}}$ \\
\hline Yes & 41.7 & 35.7 & 68.8 & 26.7 & 21.6 & 33.9 \\
\hline \multicolumn{7}{|c|}{ Injection frequency } \\
\hline NIDU & 60.2 & 66.2 & $32.9^{\mathrm{a}}$ & 73.3 & 78.8 & $66.5^{\mathrm{a}}$ \\
\hline$<$ Daily & 22.0 & 12.6 & 15.2 & 11.6 & 7.5 & 12.2 \\
\hline Daily & 17.8 & 21.2 & 51.9 & 15.1 & 13.7 & 21.2 \\
\hline \multicolumn{7}{|c|}{ Drug or alcohol treatment } \\
\hline Never & 36.1 & 45.3 & $30.0^{\mathrm{b}}$ & 15.1 & 29.7 & $25.5^{\mathrm{b}}$ \\
\hline Ever & 63.9 & 54.8 & 70.0 & 84.9 & 70.3 & 74.5 \\
\hline \multicolumn{7}{|c|}{ Alcohol use in last 6 months } \\
\hline Daily & 9.2 & 15.1 & 6.3 & 16.3 & 19.3 & 17.1 \\
\hline$<$ Daily & 90.8 & 84.9 & 93.8 & 83.7 & 80.7 & 82.9 \\
\hline \multicolumn{7}{|c|}{ Cocaine use in last 6 months } \\
\hline Daily & 20.0 & 18.7 & 23.0 & 13.3 & 14.8 & 16.4 \\
\hline$<$ Daily & 80.0 & 81.3 & 77.0 & 86.8 & 85.2 & 83.6 \\
\hline \multicolumn{7}{|c|}{ Crack use in last 6 months } \\
\hline Daily & 24.3 & 23.4 & 23.9 & 22.2 & 27.3 & 27.2 \\
\hline$<$ Daily & 75.7 & 76.6 & 76.1 & 77.8 & 72.7 & 72.8 \\
\hline \multicolumn{7}{|c|}{ Heroin use in last 6 months } \\
\hline Daily & 31.7 & 34.2 & $53.8^{\mathrm{a}}$ & 26.7 & 31.4 & 34.7 \\
\hline$<$ Daily & 68.3 & 65.8 & 46.3 & 73.3 & 68.6 & 65.3 \\
\hline \multicolumn{7}{|c|}{ Used NEP in last 6 months } \\
\hline Never & 58.0 & 71.4 & 55.6 & 47.8 & 52.9 & 50.6 \\
\hline Ever & 42.0 & 28.6 & 44.4 & 52.2 & 47.1 & 49.4 \\
\hline \multicolumn{7}{|c|}{ IDU sex partner } \\
\hline Never & 80.8 & 83.9 & 90.0 & 86.1 & 88.6 & 82.7 \\
\hline Ever & 19.2 & 16.1 & 10.0 & 13.0 & 11.4 & 17.1 \\
\hline \multicolumn{7}{|c|}{ Hepatitis positive sex partner } \\
\hline No & 93.3 & 97.5 & 96.3 & 93.0 & 95.2 & 91.8 \\
\hline Yes & 6.7 & 2.5 & 3.8 & 7.0 & 4.8 & 8.2 \\
\hline
\end{tabular}

\section{HBV Among Participants 25 years of Age and Older}

Among the 812 participants 25 years of age and older, $60 \%$ were susceptible to $\mathrm{HBV}, 30 \%$ showed evidence of current or past infection, and $10 \%$ had serologic evidence of vaccination. The sample was predominantly male $(71 \%)$ and Hispanic $(54.1 \%)$. About half of the participants in this group had a high school diploma or equivalent, and $43.2 \%$ had an illegal main source of income. Table 1 shows the sociodemographic characteristics of drug users 25 years of age and older by serologic evidence of $\mathrm{HBV}$ vaccination.
Those with evidence of previous HBV infection were more likely to be heterosexual, homeless, to have an illegal source of income, and to be seropositive for HCV and HIV than those who were susceptible or vaccinated.

Table 2 describes drug use and sexual behavior stratified by HBV serostatus. Of 210 NIDUs, $27 \%$ were found to have evidence of previous HBV infection whereas $40 \%$ of IDUs showed evidence of previous infection. As with those younger under 25 years of age, those infected with HBV were more likely to be injectors, inject drugs daily, attend a shooting gallery (data not shown), than those vaccinated or 
Table 3 Generalized polychotomous logit model of HBV serostatus among 399 drug users of age younger than 25 years old

\begin{tabular}{|c|c|c|c|c|c|c|}
\hline & \multicolumn{2}{|c|}{ Infected/susceptible } & \multirow[t]{2}{*}{$P$} & \multicolumn{2}{|c|}{ Vaccinated/susceptible } & \multirow[t]{2}{*}{$p$} \\
\hline & $\begin{array}{l}\text { Crude odds ratio } \\
(95 \% \mathrm{CI})\end{array}$ & $\begin{array}{l}\text { Adjusted odds ratio } \\
(95 \% \mathrm{CI})\end{array}$ & & $\begin{array}{l}\text { Crude odds ratio } \\
(95 \% \mathrm{CI})\end{array}$ & $\begin{array}{l}\text { Adjusted odds ratio } \\
(95 \% \mathrm{CI})\end{array}$ & \\
\hline Age $<22$ years old & $\begin{array}{l}1.38 \\
(0.82,2.34)\end{array}$ & $\begin{array}{l}1.40 \\
(1.03,1.90)\end{array}$ & 0.03 & $\begin{array}{l}2.53 \\
(1.59,4.03)\end{array}$ & $\begin{array}{l}1.66 \\
(1.31,2.12)\end{array}$ & $<0.01$ \\
\hline HCV positive & $\begin{array}{l}9.41 \\
(5.15,17.2)\end{array}$ & $\begin{array}{l}3.14 \\
(2.23,4.43)\end{array}$ & $<0.01$ & $\begin{array}{l}1.88 \\
(1.06,3.31)\end{array}$ & $\begin{array}{l}1.51 \\
(1.10,2.08)\end{array}$ & 0.01 \\
\hline HIV positive & $\begin{array}{l}6.32 \\
(1.59,25.1)\end{array}$ & $\begin{array}{l}2.96 \\
(1.40,6.27)\end{array}$ & $<0.01$ & $\begin{array}{l}4.64 \\
(1.21,17.9)\end{array}$ & $\begin{array}{l}2.30 \\
(1.14,4.66)\end{array}$ & 0.02 \\
\hline \multicolumn{7}{|l|}{ Birth place } \\
\hline USA & & 1.00 & & & 1.00 & \\
\hline Other countries & $\begin{array}{l}0.93 \\
(0.58,1.48)\end{array}$ & $\begin{array}{l}0.90 \\
(0.46,1.79)\end{array}$ & 0.77 & $\begin{array}{l}0.47 \\
(0.24,0.90)\end{array}$ & $\begin{array}{l}0.50 \\
(0.26,0.94)\end{array}$ & 0.03 \\
\hline Puerto Rico & $\begin{array}{l}1.80 \\
(1.33,2.44)\end{array}$ & $\begin{array}{l}1.30 \\
(0.78,2.15)\end{array}$ & 0.31 & $\begin{array}{l}0.99 \\
(0.68,1.46)\end{array}$ & $\begin{array}{l}1.28 \\
(0.81,2.03)\end{array}$ & 0.29 \\
\hline
\end{tabular}

susceptible. Those who share needles were more likely to be infected, but this was not statistically significant; however, $35 \%$ of susceptible IDUs reported sharing needles and $24 \%$ of susceptible IDUs attended a shooting gallery (data not shown). Although not statistically significant, HBV infected individuals were also more likely to have had a hepatitis-positive sex partner than those who were vaccinated or susceptible.

In a final multivariable polychotomous logit model (Table 4) with "uninfected/no serological evidence of vaccine" as the reference, we found that previous HBV infection was associated with being Black $(\mathrm{AOR}=1.66)$, being homeless $\quad(\mathrm{AOR}=1.37)$ being homosexual/bisexual $(\mathrm{AOR}=1.35), \mathrm{HCV}$ seropositive $(\mathrm{AOR}=2.00)$ and $\mathrm{HIV}$ seropositive $(A O R=1.91)$. There were no significant correlates of vaccination in this group, other than self-report. Because of the low reliability of self-report in this population, we excluded this variable from the multivariate models.

\section{Discussion}

In this sample of recently initiated heroin, crack and cocaine users in New York City, more than half had

Table 4 Generalized polychotomous logit model of HBV serostatus among 812 drug users 25 years of age and older

\begin{tabular}{|c|c|c|c|c|c|c|}
\hline & \multicolumn{2}{|l|}{ Infected/susceptible } & \multirow[t]{2}{*}{$P$} & \multicolumn{2}{|c|}{ Vaccinated/susceptible } & \multirow[t]{2}{*}{$p$} \\
\hline & $\begin{array}{l}\text { Crude odds ratio } \\
\text { (95\% C.I) }\end{array}$ & $\begin{array}{l}\text { Adjusted odds ratio } \\
(95 \% \mathrm{CI})\end{array}$ & & $\begin{array}{l}\text { Crude odds ratio } \\
(95 \% \mathrm{CI})\end{array}$ & $\begin{array}{l}\text { Adjusted odds ratio } \\
(95 \% \mathrm{CI})\end{array}$ & \\
\hline \multicolumn{7}{|l|}{ Race } \\
\hline White & & 1.00 & & & 1.00 & \\
\hline Black & $\begin{array}{l}2.16 \\
(1.16,4.04)\end{array}$ & $\begin{array}{l}1.67 \\
(1.22,2.29)\end{array}$ & $<0.01$ & $\begin{array}{l}2.18 \\
(0.81,5.87)\end{array}$ & $\begin{array}{l}1.40 \\
(0.91,2.16)\end{array}$ & 0.13 \\
\hline Hispanic & $\begin{array}{l}1.73 \\
(0.94,3.19)\end{array}$ & $\begin{array}{l}0.95 \\
(0.70,1.28)\end{array}$ & 0.73 & $\begin{array}{l}1.89 \\
(0.72,4.99)\end{array}$ & $\begin{array}{l}1.13 \\
(0.74,1.71)\end{array}$ & 0.57 \\
\hline Homelessness & $\begin{array}{l}2.07 \\
(1.27,3.38)\end{array}$ & $\begin{array}{l}1.48 \\
(1.09,2.00)\end{array}$ & 0.01 & $\begin{array}{l}1.63 \\
(0.81,3.28)\end{array}$ & $\begin{array}{l}1.16 \\
(0.81,1.67)\end{array}$ & 0.43 \\
\hline Homosexual/bisexual & $\begin{array}{l}2.17 \\
(1.45,3.26)\end{array}$ & $\begin{array}{l}1.39 \\
(1.11,1.76)\end{array}$ & $<0.01$ & $\begin{array}{l}0.86 \\
(0.41,1.80)\end{array}$ & $\begin{array}{l}0.95 \\
(0.64,1.41)\end{array}$ & 0.81 \\
\hline Self-reported HBV vaccination & $\begin{array}{l}1.53 \\
(0.96,2.43)\end{array}$ & $\begin{array}{l}1.17 \\
(0.91,1.52)\end{array}$ & 0.22 & $\begin{array}{l}4.02 \\
(2.33,6.93)\end{array}$ & $\begin{array}{l}2.03 \\
(1.53,2.70)\end{array}$ & $<0.01$ \\
\hline $\mathrm{HCV}+$ & $\begin{array}{l}2.98 \\
(2.05,4.33)\end{array}$ & $\begin{array}{l}1.99 \\
(1.58,2.51)\end{array}$ & $<0.01$ & $\begin{array}{l}1.41 \\
(0.77,2.56)\end{array}$ & $\begin{array}{l}1.03 \\
(0.71,1.48)\end{array}$ & 0.88 \\
\hline $\mathrm{HIV+}$ & $\begin{array}{l}4.12 \\
(2.60,6.54)\end{array}$ & $\begin{array}{l}1.81 \\
(1.40,2.35)\end{array}$ & $<0.01$ & $\begin{array}{l}1.38 \\
(0.61,3.10)\end{array}$ & $\begin{array}{l}1.01 \\
(0.64,1.58)\end{array}$ & 0.97 \\
\hline
\end{tabular}


serologic susceptibility to HBV infection. Approximately $17 \%$ had been previously vaccinated for HBV, based upon serologic evidence. This is similar to reports among drug users in Seattle, Oakland, and New York City where between $14 \%$ and $17 \%$ of IDUs had previously been vaccinated against HBV [17-19], but higher than rates suggested in Baltimore in the late 1980 s [20]. However, the vaccination rates in Seattle and Oakland relied on selfreported vaccination among IDUs as opposed to the serologic testing used in this study, so comparisons should be made with caution, given the low reliability of self-report.

As expected, younger drug users were more likely to have been vaccinated [21]. In our study, $30 \%$ of the participants younger than 25 years of age showed serological evidence of vaccination (Table 1), which is consistent with the literature for this age group [18, 19]. Although the prevalence of vaccination in younger IDUs is higher than in older IDUs (10\%), vaccination among younger adults would be higher than $30 \%$, considering existing programs and recommendations from ACIP and the Centers for Disease Control and Prevention (CDC). ACIP made hepatitis B vaccine available through the Vaccines for Children program (VFC) for persons aged 0-18 years who are eligible for VFC [12]. Even though only one third of the sample finished high school, many states require HBV vaccination for entry into middle school since 1997. Moreover, during 1993-2000, it is reported that hepatitis B vaccination coverage for adolescents 13-15 years of age increased from $0 \%$ to $67 \%$, much higher than the $30 \%$ vaccination rates we found among the less than 25 year old group in 2006 [12]. Ten years have passed since the 1997 ACIP recommendations for unvaccinated adolescents and children 18 and younger. The vaccination programs, catch up schemes, and mandates may have had an impact on the higher vaccination rates seen among younger IDUs when compared to older IDUs, but it does not explain the lower than expected vaccination rates among the younger group.

In an attempt to better understand $\mathrm{HBV}$ vaccination rates in this group, we looked at school drop out rates and age of drop out, and we found no significant relationship with HBV vaccination (data not shown). Furthermore, participants less than 25 years of age who were previously infected were more likely to have been in a drug/alcohol treatment program that those vaccinated or susceptible, which represents a potential missed opportunity for vaccination. Of note, $54.8 \%$ of the susceptible participants younger than 25 have been in a drug/alcohol treatment program, all of which could have been vaccinated (Table 2).

We observed a significant relationship between place of birth and HBV vaccination status in this younger group; those born in the US were more likely to be vaccinated than those born in other countries (Table 3). A small percentage of participants were born outside of the US (9.9\%). One possible explanation for lower vaccination rates in the foreign-born group is that many of these participants may be recent immigrants from countries with different immunization requirements for school entry than the US. Another potential explanation for lower vaccination rates in this group may have to do insurance status and access to preventive health services. Lastly, health-seeking behaviors may differ significantly in this group, possibly due to variations in trust in the health care system and reliance on alternative health care sources as part of different cultural norms. Having said this, there were no racial/ethnic disparities observed in terms of vaccination rates in this group of younger IDUs.

Among the younger group, we still observed a significant relationship between age and HBV status (Table 3); those 22 years of age or younger were more likely to have evidence of HBV infection than those older than 22 years of age. It has been reported in the literature that young and recently initiated injectors are higher risk for acquiring blood-borne infections such as $\mathrm{HCV}$ and $\mathrm{HBV}$ due to unsafe injecting behaviors [22]. Our findings support this conclusion from prior studies. We also found that previous HBV vaccination was associated with being 22 years old or younger, which may reflect that the younger participants in the less than 25 year old group were more likely to have been part of the childhood vaccination scheme.

Although coverage of HBV vaccine among health care workers is about $65 \%$ [23, 24], vaccination coverage among various acknowledged risk groups has been reported to be much lower. For example, coverage among MSM ranges between $9 \%$ and $48 \%$ [13, 25-29], while coverage among STD patients ranges between $11 \%$ and $14 \%$ [30, 31]. With prevalence of HBV infection being high among drug users, and IDUs in particular, studies suggest limited coverage of HBV vaccine; i.e. between 6 and 19\% of IDUs in general are vaccinated; higher rates, but lower than expected, are reported among younger IDUs (11-32\% of IDUs younger than 24 years of age are vaccinated) [8, 18$20,27,32,33]$. Our findings are consistent with the literature on vaccination, susceptibility to $\mathrm{HBV}$, and $\mathrm{HBV}$ infection rates among younger and older IDUs.

Vaccination rates in adults remain low for several reasons: barriers to vaccination among high risk groups include lack of access to resources (i.e. health care), discomfort with the vaccines, mistrust in the medical system, and poor hepatitis knowledge [2,34-36]. It is also partly due to the lack of national programs supporting infrastructure and vaccine purchase for adults, resulting in a high percentage of missed opportunities for vaccination in drug treatment programs, syringe exchange programs (SEPs), STD clinics, and jails or detention centers [11, 18, $37,38]$. Improving vaccination rates among younger and older drug users is an important step towards reducing the 
societal burden of HBV. Previous studies have documented HBV first dose vaccine acceptance rates among susceptible IDUs in the United States between 3\% and $81 \%$ (median $54 \%)[18,37,39]$, the higher vaccination and completion rates being reported in SEPs, drug treatment programs, or when monetary incentives were offered to participants; the lowest vaccination acceptance rates were observed in studies where participants were referred to clinics for vaccination and/or did not receive monetary incentives [18, 37, 40]. Currently, the description of vaccination efforts among drug users have been limited to overall vaccination and completion rates [36, 37, 40-43] and immune response to the vaccine [41-44], with limited data available describing the characteristics of those who have been vaccinated.

In our study, those participants 25 years old and older who had ever been in drug or alcohol treatment were significantly more likely to have been vaccinated. Other studies have reported similar results [38]. As mentioned previously, one of the barriers to vaccine acceptance is poor knowledge of hepatitis $\mathrm{B}$, and having participated in a drug treatment program has been associated with enhanced knowledge of hepatitis B [17]. This may suggest that education provided about hepatitis B in drug treatment programs is effectively acquired and retained, and this could minimize barriers to vaccine acceptance. Higher rates of vaccination among those who have ever participated in drug and alcohol treatment programs may also be due to vaccination services in treatment settings or may be a proxy for being more likely to seek treatment. Because we do not have data on where individuals were vaccinated, this finding could not be explored further in this study. However, a high percentage of participants who have been in a drug/alcohol treatment programs were susceptible to HBV (54.8\%), which, as in the younger group, may represent missed opportunities for vaccination.

Approximately one fourth of the study sample had been previously infected with HBV. IDUs were more likely to have been HBV-infected than NIDUs (35.8\% vs. 22.7\%) (Table 2). However, as this and previous studies have demonstrated [45-47], HBV infection among NIDUs is not negligible. Recent studies report that between 19\% and $21.6 \%$ of NIDUs had been previously infected with HBV $[16,38]$; these rates are much higher than the 5\% rate found in the general population [2]. Higher than expected rates of infection can be also observed in the less than 25 year old group, where $11 \%$ of the NIDUs were HBV infected. Our findings highlight the importance of NIDUs in HBV transmission. NIDUs are at risk for HBV acquisition due to risky sexual behavior $[45,47]$ and risky sexual networks [45], and we cannot rule out the possibility of transmission through risky non-injection drug using etiquette (such as sharing straws or hot pipes that abrade the mucosal lining), and as other studies has shown, household contact transmission [48, 49]. NIDUs are also at risk for transition into injection drug use. Previous studies have demonstrated that the period of transition from sniffing or smoking to injection can be particularly risky, as the new injector learns a new set of skills $[50,51]$ and becomes acquainted with new social networks [52]. During this critical transition period, the new injector is at a particularly high-risk for HBV, as well as HIV and HCV. It is therefore imperative that non-injection users of heroin, crack and cocaine be vaccinated for HBV.

Identifying as Black, homosexual/bisexual, and injection drug use were all associated with HBV infection. Previous studies have demonstrated an increased risk for HBV among IDUs [20] and homosexual/bisexual men [53]. A recent study examined HBV infection among veterans with severe mental illness and reported higher rates of HBV among Black veterans as compared to White veterans that was associated with difference in rates of high risk drug use and sexual behaviors [54]. In order to evaluate this, we investigated potential racial/ethnic differences with respect to drug use and sexual behaviors. While Blacks were significantly less likely to have injected drugs, injected drugs at a younger age, inject drugs daily, share needles, go to a shooting gallery, use cocaine and heroin daily, and have sex with an IDU as compared to Hispanics and Whites/Others, they were significantly more likely to have used crack daily in the last six months and to have had sex with an MSM (data not shown), and these two risk behaviors are associated to previous HBV infection $[2,19]$. Although this cannot completely explain the racial/ethnic differences we observed, it does suggest that the risk behaviors differ between the racial/ethnic groups. Another possible explanation could be a higher prevalence of HBV among the social networks of the Black participants, although data were not available to examine this in detail. We did ask about hepatitis-infected sex partners and did not find any significant differences with respect to race.

This study also provided important insight into the validity of self-reported HBV vaccination among drug users. With serological evidence of HBV vaccination considered the "gold standard," the sensitivity and specificity of self-reported HBV vaccination was $48.5 \%$ and $79.0 \%$, respectively in this study. However, the kappa statistic was low (0.23), indicating that reliability of selfreport data is fair, at best, in this case [55]. The lower sensitivity that we observed may be due to a waning of antibody response to a previously administered vaccine or inaccurate self-reported vaccination history. These findings suggest that self-reported HBV vaccination status may not be valid and serological confirmation is warranted. Furthermore, self-report of previous vaccination should not be considered a contraindication for provision of vaccine. In 
the worst case scenario, the extra dose of vaccine would act as a booster dose, and it would not affect those actively infected. Vaccine may be given while additional antibody testing results are obtained and vaccination/immunity status is confirmed.

These results must be considered in the context of the study's limitations. The study population does not represent all IDUs and NIDUs in New York City, only those who were approached in our recruitment scheme and were willing to participate. Thus, the extent to which these findings are generalizable to other situations is unclear. However, in light of the lack of published data on correlates of HBV vaccination among drug users, these data provide valuable insight.

In summary, we found that the majority of the drug users in this population were susceptible to HBV. These results may provide guidance for interventions aimed at improving HBV vaccine coverage among drug users across all age groups and especially among the higher risk younger group. Older drug users, many of whom are still susceptible to $\mathrm{HBV}$, continue to be missed by vaccination programs. Drug users will be an important target population when an HIV or HCV vaccine becomes available. Understanding some of the correlates of HBV vaccination can guide and inform strategies that will be designed for HIV and HCV vaccination programs among this high risk sub-group.

Acknowledgements This study was partly funded by Grants DA13146 and DA12801 from the National Institute on Drug Abuse. The HBV vaccinations were provided by the New York City Department of Health and Mental Hygiene. The authors would like to acknowledge the contributions of Vincent Edwards and Sandra Del Vecchio to the manuscript.

\section{References}

1. Coleman, P. J., McQuillan, G. M., Moyer, L. A., Lambert, S. B., \& Margolis, H. S. (1998). Incidence of hepatitis B virus infection in the United States, 1976-1994: Estimates from the national health and nutrition examination surveys. Journal of Infectious Diseases, 178(4), 954-959.

2. Centers for Disease Control and Prevention. Hepatitis Surveillance. Atlanta: U.S. Department of Health and Human Services, Centers for Disease Control and Prevention; 2005. Report No.: 60.

3. Margolis, H. S., Coleman, P. J., Brown, R. E., Mast, E. E., Sheingold, S. H., \& Arevalo, J. A. (1995). Prevention of hepatitis $\mathrm{B}$ virus transmission by immunization. An economic analysis of current recommendations. JAMA, 274(15), 1201-1208.

4. Custer B., Sullivan S. D., Hazlet T. K., Iloeje U., Veenstra D. L., \& Kowdley, K. V. (2004). Global epidemiology of hepatitis B virus. Journal of Clinical Gastroenterology, 38(10 Suppl), S158S168.

5. Glynn, S. A., Kleinman, S. H., Schreiber, G. B., et al. (2000). Trends in incidence and prevalence of major transfusion-transmissible viral infections in US blood donors, 1991 to 1996.
Retrovirus Epidemiology Donor Study (REDS). JAMA, 284(2), 229-235.

6. Alter, M. J., Hadler, S. C., Margolis, H. S., et al. (1990). The changing epidemiology of hepatitis B in the United States. Need for alternative vaccination strategies. JAMA, 263(9), 1218-1222.

7. Murrill, C. S., Weeks, H., Castrucci, B. C., et al. (2002). Agespecific seroprevalence of $\mathrm{HIV}$, hepatitis $\mathrm{B}$ virus, and hepatitis $\mathrm{C}$ virus infection among injection drug users admitted to drug treatment in 6 US cities. American Journal of Public Health, 92(3), 385-387.

8. Hepatitis B vaccination for injection drug users-Pierce County, Washington, 2000. (2001). MMWR Morbidity and Mortality Weekly Report, 50(19), 388-390, 399.

9. Advisory Committee on Immunization Practices. (1991). Hepatitis B virus: A comprehensive strategy for eliminating transmission in the United States through universal childhood vaccination: Recommendations of the Immunization Practices Advisory Committee. MMWR Morbidity and Mortality Weekly Report 40(RR13), 1-25.

10. American Academy of Pediatrics CoID (1992). Universal hepatitis B vaccination. Pediatrics, $89,795-800$.

11. Hepatitis B vaccination coverage among adults-United States, 2004. (2006). MMWR Morbidity and Mortality Weekly Report, 55(18), 509-511.

12. Mast, E. E., Margolis, H. S., Fiore, A. E., et al. (2005). A comprehensive immunization strategy to eliminate transmission of hepatitis B virus infection in the United States: Recommendations of the advisory committee on immunization practices (ACIP) part 1: Immunization of infants, children, and adolescents. MMWR Morbidity and Mortality Weekly Report, 54 (RR-16), 1-31.

13. MacKellar, D. A., Valleroy, L. A., Secura, G. M., et al. (2001). Two decades after vaccine license: Hepatitis B immunization and infection among young men who have sex with men. American Journal of Public Health, 91(6), 965-971.

14. Diaz, T., Des, J., Vlahov, D., et al. (2001). Factors associated with prevalent hepatitis C: Differences among young adult injection drug users in lower and upper Manhattan, New York City. American Journal of Public Health, 91(1), 23-30.

15. Diaz, T., Vlahov, D., Greenberg, B., Cuevas, Y., \& Garfein, R. (2001). Sexual orientation and HIV infection prevalence among young Latino injection drug users in Harlem. Journal of Womens Health Gender Based Medicine, 10(4), 371-380.

16. Ompad, D. C., Galea, S., Wu, Y., et al. (2004). Acceptance and completion of hepatitis B vaccination among drug users in New York City. Communicable Disease and Public Health, 7(4), 294-300.

17. Heimer, R., Clair, S., Grau, L. E., Bluthenthal, R. N., Marshall, P. A., \& Singer, M. (2002). Hepatitis-associated knowledge is low and risks are high among HIV-aware injection drug users in three US cities. Addiction, 97(10), 1277-1287.

18. Hagan, H., Thiede, H., McGough, J. P., \& Alexander, E. R. (2002). Hepatitis B vaccination among research participants, Seattle, Washington. American Journal of Public Health, 92(11), 1756.

19. Kottiri, B. J., Friedman, S. R., Euler, G. L., et al. (2005). A community-based study of hepatitis B infection and immunization among young adults in a high-drug-use neighborhood in New York City. Journal of Urban Health, 82(3), 479-487.

20. Levine, O. S., Vlahov, D., Koehler, J., Cohn, S., Spronk, A. M., \& Nelson, K. E. (1995). Seroepidemiology of hepatitis B virus in a population of injecting drug users. Association with drug injection patterns. American Journal of Epidemiology, 142(3), 331-341.

21. Immunization Action Coalition. Hepatitis B Prevention Mandates. 1-31-2006. Ref Type: Internet Communication.

22. Garfein, R. S., Vlahov, D., Galai, N., Doherty, M. C., \& Nelson, K. E. (1996). Viral infections in short-term injection drug users: 
The prevalence of the hepatitis $\mathrm{C}$, hepatitis $\mathrm{B}$, human immunodeficiency, and human T-lymphotropic viruses. American Journal of Public Health, 86(5), 655-661.

23. Gershon, R. R., Mitchell, C., Sherman, M. F., et al. (2005). Hepatitis B vaccination in correctional health care workers. American Journal of Infection Control, 33(9), 510-518.

24. Mahoney, F. J., Stewart, K., Hu, H., Coleman, P., \& Alter, M. J. (1997). Progress toward the elimination of hepatitis B virus transmission among health care workers in the United States. Archives of Internal Medicine, 157(22), 2601-2605.

25. Rhodes, S. D., \& Hergenrather, K. C. (2002). Exploring hepatitis $B$ vaccination acceptance among young men who have sex with men: facilitators and barriers. Preventive Medicine, 35(2), 128134.

26. Rhodes, S. D., DiClemente, R. J., Yee, L. J., \& Hergenrather, K. C. (2001). Correlates of hepatitis B vaccination in a high-risk population: an Internet sample. American Journal of Medicine, $110(8), 628-632$.

27. Hepatitis B vaccination among high-risk adolescents and adultsSan Diego, California, 1998-2001. (2002). MMWR Morbidity and Mortality Weekly Report, 51(28), 618-621.

28. Remis, R. S., Dufour, A., Alary, M., et al. (2000). Association of hepatitis B virus infection with other sexually transmitted infections in homosexual men. Omega Study Group. American Journal of Public Health, 90(10), 1570-1574.

29. Zimet, G. D., Kee, R., Winston, Y., Perkins, S. M., \& Maharry, K. (2001). Acceptance of hepatitis B vaccination among adult patients with sexually transmitted diseases. Sexually Transmitted Diseases, 28(11), 678-680.

30. Sellors, J., Zimic-Vincetic, M., Howard, M., Mahony, J. B., \& Chernesky, M. A. (1998). Predictors of positivity for hepatitis B and the derivation of a selective screening rule in a Canadian sexually transmitted disease clinic. Journal of Clinical Virology, 11(1), 85-91.

31. Folstein, M. F., Bassett, S. S., Anthony, J. C., Romanoski, A. J., \& Nestadt, G. R. (1991). Dementia: Case ascertainment in a community survey. Journal of Gerontology, 46(4), M132-M138.

32. Thiede, H., Romero, M., Bordelon, K., Hagan, H., \& Murrill, C. S. (2001). Using a jail-based survey to monitor HIV and risk behaviors among Seattle area injection drug users. Journal of Urban Health, 78(2), 264-278.

33. Carey, J., Perlman, D. C., Friedmann, P., et al. (2005). Knowledge of hepatitis among active drug injectors at a syringe exchange program. Journal of Substance Abuse Treatment, 29(1), 47-53.

34. Samoff, E., Dunn, A., VanDevanter, N., Blank, S., \& Weisfuse, I. B. (2004). Predictors of acceptance of hepatitis B vaccination in an urban sexually transmitted diseases clinic. Sexually Transmitted Diseases, 31(7), 415-420.

35. Seal, K. H., Ochoa, K. C., Hahn, J. A., Tulsky, J. P., Edlin, B. R., \& Moss, A. R. (2000). Risk of hepatitis B infection among young injection drug users in San Francisco: Opportunities for intervention. Western Journal of Medicine, 172(1), 16-20.

36. Des Jarlais, D. C., Fisher, D. G., Newman, J. C., et al. (2001). Providing hepatitis B vaccination to injection drug users: Referral to health clinics vs on-site vaccination at a syringe exchange program. American Journal of Public Health, 91(11), 1791-1792.

37. Kuo, I., Sherman, S. G., Thomas, D. L., \& Strathdee, S. A. (2004). Hepatitis B virus infection and vaccination among young injection and non-injection drug users: Missed opportunities to prevent infection. Drug and Alcohol Dependence, 73(1), 69-78.

38. Lum, P. J., Ochoa, K. C., Hahn, J. A., Page, S. K., Evans, J. L., \& Moss, A. R. (2003). Hepatitis B virus immunization among young injection drug users in San Francisco, Calif: The UFO Study. American Journal of Public Health, 93(6), 919-923.
39. Mezzelani, P., Venturini, L., Turrina, G., Lugoboni, F., \& Des, J. (1991). High compliance with a hepatitis B virus vaccination program among intravenous drug users. Journal of Infectious Diseases, 163(4), 923.

40. Quaglio, G., Talamini, G., Lugoboni, F., et al. (2002). Compliance with hepatitis B vaccination in 1175 heroin users and risk factors associated with lack of vaccine response. Addiction, 97(8), 985-992.

41. Borg, L., Khuri, E., Wells, A., et al. (1999). Methadone-maintained former heroin addicts, including those who are anti-HIV-1 seropositive, comply with and respond to hepatitis B vaccination. Addiction, 94(4), 489-493.

42. Rodrigo, J. M., Serra, M. A., Aparisi, L., et al. (1992). Immune response to hepatitis $\mathrm{B}$ vaccine in parenteral drug abusers. Vaccine, 10(11), 798-801.

43. Rumi, M., Colombo, M., Romeo, R., et al. (1991). Suboptimal response to hepatitis B vaccine in drug users. Archives of Internal Medicine, 151(3), 574-578.

44. Gyarmathy, V. A., Neaigus, A., Miller, M., Friedman, S. R., \& Des, J. (2002). Risk correlates of prevalent HIV, hepatitis B virus, and hepatitis $\mathrm{C}$ virus infections among noninjecting heroin users. Journal of Acquired Immune Deficiency Syndromes, 30(4), 448-456.

45. Hwang, L. Y., Ross, M. W., Zack, C., Bull, L., Rickman, K., \& Holleman, M. (2000). Prevalence of sexually transmitted infections and associated risk factors among populations of drug abusers. Clinical of Infectious Diseases, 31(4), 920-926.

46. Thomas, D. L., Cannon, R. O., Shapiro, C. N., Hook, E. W. III, Alter, M. J., \& Quinn, T. C. (1994). Hepatitis C, hepatitis B, and human immunodeficiency virus infections among non-intravenous drug-using patients attending clinics for sexually transmitted diseases. Journal of Infectious Diseases, 169(5), 990-995.

47. Friedland, G. H., Saltzman, B. R., Rogers, M. F., et al. (1986). Lack of transmission of HTLV-III/LAV infection to household contacts of patients with AIDS or AIDS-related complex with oral candidiasis. New England Journal of Medicine, 314(6), 344-349.

48. Nordenfelt, E., \& Dahlquist, E. (1978). HBsAg positive adopted children as a cause of intrafamilial spread of hepatitis B. Scandinavian Journal of Infectious Diseases, 10(3), 161-163.

49. Carneiro, M., Fuller, C., Doherty, M. C., \& Vlahov, D. (1999). HIV prevalence and risk behaviors among new initiates into injection drug use over the age of 40 years old. Drug and Alcohol Dependence, 54(1), 83-86.

50. van Ameijden, E. J., van den Hoek, J. A., Hartgers, C., \& Coutinho, R. A. (1994). Risk factors for the transition from noninjection to injection drug use and accompanying AIDS risk behavior in a cohort of drug users. American Journal of Epidemiology, 139, 1153-1163.

51. Fuller, C. M., Vlahov, D., Latkin, C. A., Ompad, D. C., Celentano, D. D., \& Strathdee, S. A. (2003). Social circumstances of initiation of injection drug use and early shooting gallery attendance: Implications for HIV intervention among adolescent and young adult injection drug users. Journal of Acquired Immune Deficiency Syndrome, 32(1), 86-93.

52. Francis, D. P., Hadler, S. C., Prendergast, T. J., et al. (1984). Occurrence of hepatitis A, B, and non-A/non-B in the United States. CDC sentinel county hepatitis study I. American Journal of Medicine, 76(1), 69-74.

53. Butterfield, M. I., Bosworth, H. B., Stechuchak, K. M., et al. (2004). Racial differences in hepatitis B and hepatitis C and associated risk behaviors in veterans with severe mental illness. Journal of Natural Medicine Association, 96(1), 43-52.

54. Landis, J. R., \& Koch, G. G. (1977). The measurement of observer agreement for categorical data. Biometrics, 33(1), 159-174. 